Artigo

\title{
Padrões de Variabilidade de Vazão de Rios nas Principais Bacias Brasileiras e Associação com Índices Climáticos
}

\author{
Caluan Rodrigues Capozzoli ${ }^{1,3}$, Andrea de Oliveira Cardoso ${ }^{1}$, \\ Simone Erotildes Teleginski Ferraz ${ }^{2}$ \\ ${ }^{1}$ Centro de Engenharia Modelagem e Ciências Socias Aplicadas, \\ Universidade Federal do ABC, Santo André, SP, Brasil. \\ ${ }^{2}$ Departamento de Física, Universidade Federal de Santa Maria, Santa Maria, RS, Brasil. \\ ${ }^{3}$ Gerência de Hidrologia e Gestão Territorial, Departamento de Hidrologia, \\ Companhia de Pesquisa de Recursos Minerais, São Paulo, SP, Brasil.
}

Recebido em 30 de Março de 2016 - Aceito em 2 de Janeiro de 2017

\begin{abstract}
Resumo
O objetivo deste estudo é caracterizar os principais padrões de variabilidade espaço-temporal de vazões e relacioná-los com padrões climáticos que podem afetar tal variável. Para tanto, foi aplicada a Análise de Componentes Principais sobre o conjunto de dados de vazão de rios brasileiros, onde cada Componente Principal encontrado se associa a um modo de variabilidade de vazão. A variabilidade temporal dos seis primeiros modos (que explicam mais de $80 \%$ da variabilidade total de vazão) foi comparada com a série temporal dos índices climáticos por correlação simples e comparando densidade de potência espectral de ambos. Os principais modos de vazão de rios brasileiros apresentam flutuações interanuais associadas ao fenômeno El Niño Oscilação Sul e correlações significativas com a temperatura da superfície do mar no Atlântico tropical, o que demonstra a importância das influências remotas associadas às anomalias de temperatura da superfície do mar no oceano tropical. Padrões climáticos associados às variabilidades decadal e multidecadal dos oceanos Pacífico e Atlântico, respectivamente, possuem relações persistentes com os seis primeiros modos de vazão.
\end{abstract}

Palavras-chave: variabilidade de vazão, padrões climáticos, análise de componentes principais.

\section{River Flow Variability Patterns in Main Brazilian Basins and Association with Climate Indices}

\begin{abstract}
This work characterizes the main spatiotemporal variability present in flow series and relates these variabilities with climate patterns that could affect this variable. The Principal Component Analysis was applied over Brazilian streamflow time series, when each principal component is associated with one variability mode. The temporal variability of first six modes (that explain more than $80 \%$ of total variability) was compared with climate indexes performing a simple correlation and analyzing the power spectral density of modes and indexes. The results show similarities between variabilities patterns and climate indexes, the correlations are significant and both have spectral peaks in same frequencies. The main variability modes of river flow showed interannual fluctuations associated with El Niño Southern Oscillation phenomenon and significate correlations with sea surface temperature in the Tropical Atlantic, demonstrating the importance of remote influences associated which sea surface temperature anomalies in the tropical ocean. Climate patterns associated with multidecadal and decadal variability of the Atlantic and Pacific Oceans, respectively, have persistent relationships with the rivers flow modes.
\end{abstract}

Keywords: streamflow variability, climate patterns, principal component analysis.

Autor de correspondência: Caluan Rodrigues Capozzoli, caluan.capozzoli@cprm.gov.br, caluan@gmail.com. 


\section{Introdução}

O regime fluvial de um rio é determinado por fatores relacionados à interação entre as condições climáticas e a fisiologia da bacia (Tucci, 2009; Pruski e Brandão, 2004; Lima et al., 2015).

Além da chuva que cai diretamente sobre os rios, a precipitação sobre pontos mais distantes das bacias hidrográficas que chega ao rio principal por escoamento superficial e subsuperficial, dependendo das condições de infiltração, contribui consideravelmente para a vazão observada em um ponto de monitoramento fluviométrico e faz com que a resposta fluvial a uma determinada quantidade de precipitação não seja linear (Chow et al., 1994). A contribuição do escoamento subterrâneo é fundamental para manter os rios perenes nos períodos de longa estiagem, sendo este um fator resultante da capacidade de infiltração da água do solo, que depende do tipo e do uso do solo (Tucci e Clarke, 1997). No que se refere à recarga dos aquíferos, os tipos de chuvas e a qualidade da estação chuvosa desempenha um papel fundamental. Neste sentido, é evidente a forte relação entre as variabilidades na precipitação e na vazão.

Os totais pluviométricos da climatologia mensal e o período de ocorrência da estação seca ou chuvosa são diferenciados para várias regiões do país (Quadro et al., 1996; Grimm, 2003).

No Sul do Brasil, as frentes frias e os sistemas convectivos de mesoescala são os principais causadores de chuvas durante o ano (Quadro et al., 1996; Reboita et al., 2010). Muitas vezes a parte sul da Região Sudeste é alcançada por esses sistemas transientes e então há ocorrência de chuvas (Vera et al., 2006; Kousky e Cavalcanti., 1984). A estação chuvosa, em grande parte do Brasil (Sudeste, Centro-Oeste e faixa norte da Região Sul) ocorre no verão, associada principalmente à atuação da Zona de Convergência do Atlântico Sul (ZCAS) (Kousky, 1988; Kodama, 1992; Grimm et al., 2000). Em parte do nordeste brasileiro a qualidade da estação chuvosa é principalmente influenciada pelo posicionamento da Zona de Convergência Intertropical (ZCIT) (Kouadio et al., 2012; Moura e Shukla, 1981), cujas características são influenciadas pelo gradiente inter-hemisférico de temperatura da superfície do mar (TSM) no Oceano Atlântico equatorial (Chiang et al., 2002). No Norte do Brasil, o máximo de precipitação no outono e no inverno está relacionado com a migração anual de convecção tropical profunda. $\mathrm{O}$ ar úmido trazido pelos ventos de leste da ZCIT sofre levantamento orográfico sobre os Andes, condensando e favorecendo as chuvas (Marengo e Nobre, 2009; Marengo et al., 2011).

O principal fenômeno de grande escala que pode influenciar a precipitação (entre outras variáveis meteorológicas) é o El Niño Oscilação Sul (ENOS), cujos episódios podem causar anomalias de precipitação em todo o globo (Ropelewski e Halpert, 1987). No Brasil, ocorrem anomalias positivas (negativas) de precipitação sobre o Sul do
Brasil na primavera de El Niño (La Niña) e no outono e inverno do ano seguinte a esses episódios (Grimm, 2009). O sudeste do Brasil é uma região de transição caracterizada por anomalias de chuva com sinais opostos, definindo a fronteira entre as condições secas no Nordeste e chuvosas no Sul (Coelho et al., 2002).

Diferenças nos padrões de precipitação associados ao ENOS podem também estar relacionadas à fase da Oscilação Decadal do Pacífico (PDO), que influencia construtivamente o ENOS, quando estiver na mesma fase (Kayano e Andreoli, 2009a). A precipitação do Nordeste brasileiro relaciona-se com a circulação de inverno do Hemisfério Norte por meio do ENOS (Kayano e Andreoli, 2009b), podendo envolver o padrão Pacífico América do Norte (PNA) e a Oscilação do Atlântico Norte (NAO). Anomalias de TSM no Oceano Atlântico tropical influenciam a precipitação do Nordeste juntamente com o ENOS (Andreoli e Kayano, 2007).

A influência do ENOS sobre cotas e vazões de rios foi explorada por diversos autores, sendo observada na variabilidade do regime de vazão de rios das Américas, Europa e Austrália (Dettinger e Diaz, 2000; Dettinger et al., 2000), África (Amarasekera et al., 1997) e China (Miao e Ni, 2009). Um padrão de anomalias de vazão semelhante ao de precipitação durante eventos de El Niño/La Niña é observado na América do Sul (Dettinger et al., 2000). Grimm e Tedeschi (2009) destacaram a influência dos eventos ENOS sobre a frequência de extremos de vazão na América do Sul, na região das bacias do Paraguai e Uruguai (Brasil central), o aumento (diminuição) de extremos de vazão está relacionado com a ocorrência de eventos El Niño (La Niña) (Tedeschi e Grimm, 2008).

Também há evidências consistentes do impacto do ENOS sobre a vazão no Rio Paraná, indicando maiores (menores) vazões médias durante o ano de início do fenômeno e até meados do ano seguinte ao El Niño (La Niña) (Berri et al., 2002), havendo ainda relações significativas entre a TSM dos CPs do ENOS e o regime fluvial do Rio Paraná (Cardoso e Silva Dias, 2006).

Na bacia Amazônica é observado que em termos de vazão e precipitação, os anos de El Niño são mais secos do que anos de La Niña (Coelho et al., 2012).

O El Niño Modoki pode influenciar algumas áreas da América do Sul, por exemplo, Regiões Sul e Nordeste do Brasil, de forma oposta ao observado em anos do El Niño Canônico (Tedeschi et al., 2012), sendo destacada uma alta frequência de eventos extremos de vazões baixas no Rio Paranaíba, durante o período sazonal de cheias, em anos de El Niño Modoki (Sahu et al., 2014).

A influência de outros padrões climáticos e de teleconexões no regime de vazão de rios brasileiros também tem sido analisada, sendo encontradas influências da TSM do Pacífico e Atlântico nos rios Paraná e Uruguai (Robertson e Mechoso, 1998); PDO; Oscilação Multidecadal do Atlântico; Oscilação Antártica (Cardoso e Cataldi, 2012). 
É evidente a grande variedade de mecanismos que influenciam o padrão de chuvas sobre o Brasil e, consequentemente, impactam o regime de vazão. Em termos sazonais, os padrões de vazão nas bacias brasileiras apresentam grandes semelhanças à sazonalidade da precipitação sobre o país, apresentada em Grimm (2003), reforçando o fato de que a distribuição da precipitação interfere de forma representativa no regime de vazão de rios (Cardoso et al., 2011).

Os principais sistemas atmosféricos da alta e baixa troposfera que atuam sobre a América do Sul e influenciam os padrões de precipitação são bem conhecidos, sendo caracterizadas cinco regiões sobre o Brasil com semelhantes padrões sazonais de precipitação e sistemas atuantes, de acordo com Reboita et al. (2010). Quando a variável de estudo é a precipitação, pode ser considerada a influência de sistemas transientes ou de grande escala, sem limitações geográficas, o que não acontece no caso de vazão de rios, pois esta depende da área de drenagem da bacia. Bacias mais extensas, como as bacias do São Francisco, Paraná, Tocantins e Amazonas, por exemplo, podem ser influenciadas por diferentes sistemas meteorológicos em escala de tempo variada.

Associando a grande variabilidade (espacial e temporal) dos sistemas meteorológicos que atuam no Brasil com a não linearidade da resposta fluvial a precipitação, identificar padrões climáticos determinantes para variação de vazão se torna um problema complexo, visto que fenômenos climáticos exercem influências em regiões preferenciais, mas dependendo do local da bacia essa área afetada pode causar influências indiretas em outros pontos.

Conhecer os principais padrões climáticos associados à variabilidade fluvial é importante para compreensão dos processos hidrológicos que podem auxiliar, por exemplo, o aperfeiçoamento de modelos hidrológicos do tipo chuvavazão (Chahine, 1992).

Dentro desse contexto, este trabalho utiliza o método multivariado conhecido como Análise de Componentes Principais (ACP) para identificar os principais padrões espaciais e temporais de variabilidade de vazão de rios brasileiros e suas correlações com padrões climáticos.

\section{Dados e Metodologia}

\subsection{Dados utilizados}

Foram utilizados dados históricos mensais de vazão natural de 163 pontos, em locais de aproveitamentos hidroelétricos (Fig. 1), disponibilizados pelo Operador Nacional do Sistema Elétrico, no período de 1931 a 2008. A vazão naturalizada se refere à vazão correspondente que ocorreria em uma seção de rio se não houvesse ação antrópica na área de drenagem contribuinte da seção e, além da observação hidrológica, inclui elementos de balanço hídrico (Guetter et al., 2002). Conforme pode ser observado na Fig. 1, há grande diferença nas amplitudes das vazões ao longo de

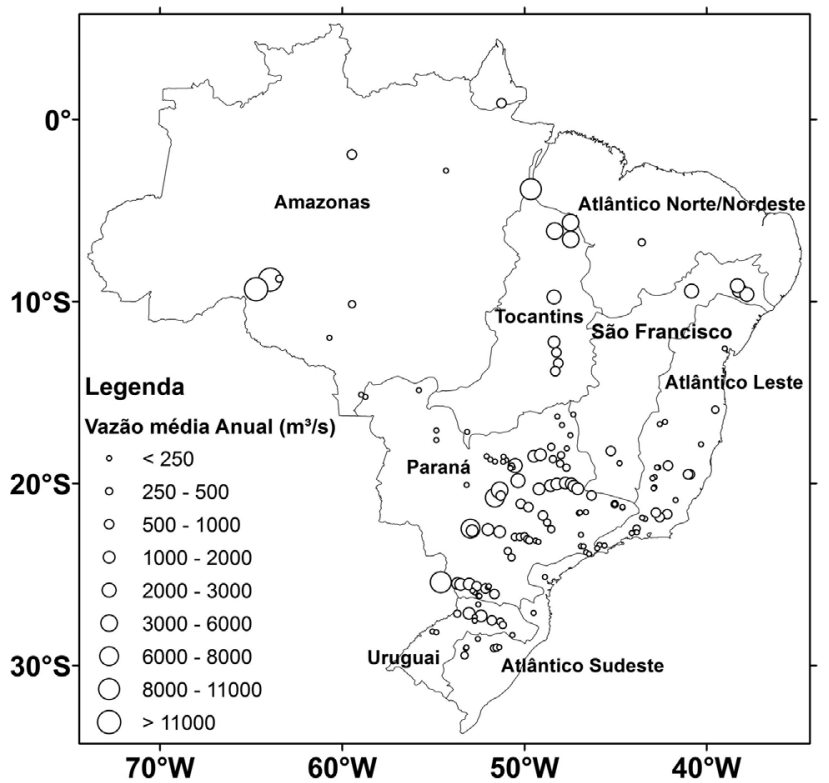

Figura 1 - Vazão média anual dos 163 postos de vazão naturalizada utilizados para o estudo.

uma bacia e entre diferentes bacias. Assim, para que este conjunto de dados seja representado em escalas comparáveis, as séries de vazão foram padronizadas pela média e desvio padrão mensais, removendo o ciclo sazonal e evidenciando as demais variabilidades existentes.

Também foram utilizadas séries de índices climáticos disponíveis na página do National Oceanic and Atmospheric Administration - NOAA, listados a seguir: Índice de Oscilação Sul (IOS); Oscilação do Atlântico Norte (NAO); Oscilação Multidecadal do Atlântico (AMO); Anomalia de TSM no Atlântico tropical sul (TSA) e norte (TNA); Oscilação Decadal do Pacífico (PDO); Anomalia de TSM na área Niño 3.4 (N3.4); Oscilação Quase Bienal (QBO); Modo Meridional do Atlântico (AMM); e Oscilação Antártica (AAO). Em adição, foi utilizado o Índice do Oceano Índico (IOD - SAJI et al., 1999). Este foi calculado utilizando dados de temperatura da superfície do mar do conjunto GISST disponibilizado pelo Met Office Hadley Centre. A maior parte dos índices inicia em meados de 1950, no entanto foi considerado o período de 1979 a 2008, pois o registro histórico do AAO iniciou mais tarde.

\subsection{Identificação de padrões de variabilidade de vazão, periodicidades e relações}

Para identificar os padrões de variabilidade presentes nos dados mensais de vazão de rios nas diferentes bacias brasileiras, foi aplicado o método multivariado conhecido como Análise de Componentes Principais (ACP), também conhecido como Funções Ortogonais Empíricas (EOF sigla em inglês para Empirical Orthogonal Function), sobre os dados de vazão padronizada. A ACP é uma técnica destinada para análise da variabilidade de um campo simples, ou seja, um campo de somente uma variável escalar. 
Além de reduzir o número de variáveis do conjunto original, este método encontra os padrões espaciais de variabilidade e suas variações no tempo, fornecendo a medida da importância de cada padrão.

Segundo Weare e Nasstrom (1982) este método fornece uma descrição satisfatória das variações de um campo complexo a partir de um número relativamente pequeno de funções. A ACP determina os autovalores e os autovetores de uma matriz de covariância amostral. Os componentes principais (ou modos) são obtidos através de combinações lineares entre as variáveis originais e os autovetores. Os autovalores fornecem a variância explicada por cada modo, sendo que a ordem do modo aumenta com a diminuição da variância (Wilks, 1995).

Para obter os componentes principais, os dados originais (vazão média mensal padronizada) foram dispostos em uma matriz $[\mathbf{X}]$ onde cada uma das colunas representa a série temporal de vazão média mensal padronizada de um ponto de monitoramento. A partir de [X] foi calculada a matriz de covariância [S], que foi utilizada para obter os autovalores e autovetores, sendo que para dados de anomalia padronizada os autovalores e autovetores poderiam ter sido obtidos a partir da matriz de correlações [R], pois é igual a [S].

O espectro de potência das variáveis atmosféricas varia de escalas de tempo entre cerca de 10 dias até alguns anos, e deste modo muitas flutuações climáticas podem ser entendidas como a resposta das variações lentas do clima. A transformada de Fourier da função de autocovariância é a função densidade espectral de potência, também chamada espectro. A densidade espectral mostra como a potência total (variância) está dividida sobre uma faixa de frequência. O deslocamento máximo ("lag") $m$ no cálculo da autocovariância influencia a resolução da densidade espectral. Quanto menor for $m$, menor será a largura da base da janela temporal (e maior a largura da base da correspondente janela espectral) e menor será a variância do estimador. No entanto, o estreitamento da base da janela temporal provoca uma distorção sempre maior entre o valor estimado da densidade espectral e o valor verdadeiro. É necessário buscar um equilíbrio entre variância e poder de resolução (Jenkins e Watts, 1968).

Diversos estudos utilizam a densidade espectral para mostrar quais as escalas de variabilidade (ou ciclos significativos) tem maiores potência em uma série temporal (D’Almeida, 1997; Liebmann et al., 1999; Paegle et al., 2000). Portanto, com o objetivo de identificar os ciclos mais significativos de cada modo de vazão, foi calculada a densidade espectral de potências das séries temporais dos seis primeiros CPs (scores) e dos índices climáticos, usando diferentes deslocamentos máximos (lags), o que permite detectar ciclos com diferentes frequências. Assim, calculou-se a densidade espectral para os lags de 30, 60, 120 e 480 meses, com o objetivo detectar diferentes escalas de variabilidade. A significância estatística ao nível de signifi- cância de 5\% foi verificada utilizando a distribuição QuiQuadrado (Jenkins e Watts, 1968; Chatfield, 2004).

Para auxiliar na investigação dos possíveis padrões climáticos relacionados aos modos de vazão, foi realizada a análise de correlação simples, calculando o coeficiente $\mathrm{r}$ de Pearson entre as séries dos índices climáticos padronizados e os scores dos modos de vazão, sendo testada a significância da correlação pelo teste t-Student ao nível de significância de 5\%. Foram calculadas correlações sem defasagem ( lag 0) e defasadas, com os índices climáticos precedendo a vazão em 1 a 4 meses (lags 1 a 4).

\section{Resultados e Discussão}

Os seis primeiros CPs de vazão explicam juntos $80,8 \%$ da variância dos dados originais e foram analisados buscando a identificação de padrões relacionados a fenômenos climáticos. A Tabela 1 mostra a variância explicada pelos seis primeiros CPs, a variância acumulada e os picos espectrais significativos das séries temporais de cada CP.

O padrão espacial do primeiro $\mathrm{CP}(\mathrm{CP} 1)$, com variância explicada de $34,4 \%$, obtido pela correlação de sua série temporal com as séries de vazão de cada estação utilizada (peso do CP), é mostrado na Fig. 2, que apresenta correlações positivas com a porção oriental da Bacia do Paraná e Bacias do Tocantins, São Francisco e Atlântico Leste. A série temporal, filtrada na média móvel de 13 meses (Fig. 2b), apresenta picos positivos (negativos) nos anos de 1965-1966, 1976-1977, 1979-1980 e 1983 (1933, 1954-1955, 1963-1964, 1969 e 1971) e variações de mais baixa frequência na escala decadal, principalmente entre o final da década de 40 e final da década de 1970, sendo que a partir da década de 80 há predomínio da variabilidade interanual. Resultados da análise espectral (Tabela 1) indicaram a presença de picos significativos nas escalas semianual, interanual e decadal.

Os resultados das correlações dos índices climáticos com o primeiro CP indicam influencia do ENOS e da PDO na variabilidade capturada sobre as regiões mencionadas. Correlações positivas significativas (indicadas a partir da linha tracejada, Fig. 2c) são verificadas entre a série temporal do CP e os índices climáticos do Niño 3.4 (N3.4, associado à anomalia de TSM na região do Niño 3.4) e da PDO,

Tabela 1 - Porcentagens da variância explicada e da variância acumulada e picos espectrais significativos dos seis primeiros Componentes Principais (CPs) de vazão.

\begin{tabular}{lcc}
\hline CPs & Var. Exp. (\%)/ Var. Acum $(\%)$ & Picos espectrais (meses) \\
\hline 1 & $34,4 \% / 34,4 \%$ & $96 ; 11,7 ; 5,1 ; 3,3 ; 5 ; 4,1$ \\
2 & $23,4 \% / 57,8 \%$ & 43,$6 ; 6,2 ; 4,5 ; 3,9$ \\
3 & $9 \% / 66,8 \%$ & $137 ; 30 ; 4,9 ; 3,2$ \\
4 & $6,2 \% / 73 \%$ & 5,$9 ; 4,4$ \\
5 & $4,5 \% / 77,5 \%$ & $240 ; 137 ; 6,2 ; 4,9 ; 3,2$ \\
6 & $3,3 \% / 80,8 \%$ & $120 ; 6,2 ; 3,3$ \\
\hline
\end{tabular}



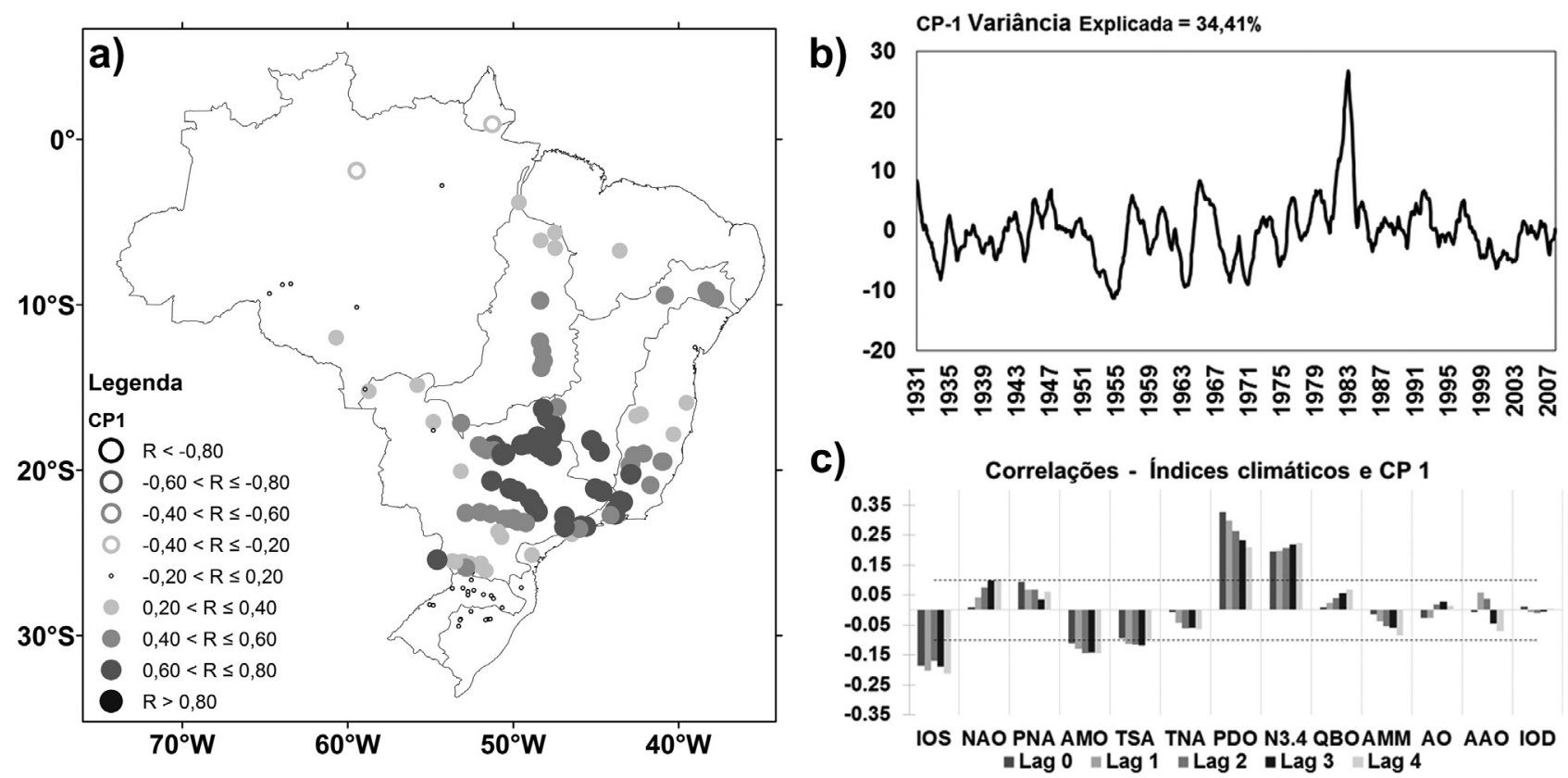

Figura 2 - Padrão espacial do primeiro componente principal de vazão (CP1) (a); Série temporal suavizada pela média móvel de 13 meses do CP1 (b) e Correlações do CP1 com os índices climáticos indicados (c) (correlações são significativas a partir da linha tracejada).

e correlações com sinal oposto com o IOS (Índice de Oscilação Sul). A significância da relação é verificada em todas as defasagens avaliadas, incluindo os índices precedendo a vazão em até 4 meses, sendo notado que no caso da PDO, os valores das correlações diminuem com a defasagem, e no caso do índice associado ao ENOS, as correlações aumentam com a defasagem, evidenciando uma defasagem no impacto do ENOS sobre a vazão. Os índices IOS e N3.4 apresentam picos em anos de eventos El Niño e La Niña (Trenberth e Stepaniak, 2001), sendo de sinais inversos para cada índice, dado que o IOS provém de uma variável atmosférica (pressão ao nível do mar) e o N3.4 de uma variável oceânica (TSM). Outros padrões destacados com correlações significativas foram AMO (Oscilação Multidecadal do Atlântico) e TSA (anomalia de TSM no Atlântico tropical sul), evidenciando a importância das variabilidades nas anomalias de TSM no Atlântico tropical e norte para a modulação da variabilidade da vazão de rios no Brasil.

Os picos espectrais do CP1 capturados na escala semianual (4 e 5 meses), interanual (11,7 meses) e decadal (96 meses) podem estar associados aos fenômenos ENOS, às oscilações decadal e multidecadal (PDO e AMO, respectivamente) e as variabilidades sazonais das anomalias no Atlântico tropical sul, via TSA. Comparando a análise espectral da série temporal do primeiro $\mathrm{CP}$ com os picos significativos dos índices (Tabela 2) é possível verificar que os picos espectrais deste $\mathrm{CP}$ correspondem ao mesmo período dos índices AMO, N3.4, TSA e PDO, concordando com o resultado das correlações.

Durante a fase positiva da PDO (1925-1946 e 19772000) houve uma maior ocorrência de eventos El Niño, enquanto que na fase negativa (1910-1924 e 1947-1976)
Tabela 2 - Picos espectrais significativos de índices climáticos.

\begin{tabular}{lc}
\hline Índice climático & Picos espectrais (meses) \\
\hline AAO & $64 ; 20 ; 2,6$ \\
AMM & $100 ; 60 ; 12$ \\
AMO & $100 ; 44 ; 12$ \\
IOD & $40 ; 12 ; 6$ \\
IOS & $60 ; 48 ; 30 ; 26 ; 17$ \\
N3.4 & $120 ; 48 ; 30 ; 26 ; 17$ \\
NAO & $30 ; 15 ; 10 ; 7 ; 3$ \\
PDO & $80 ; 15 ; 12 ; 7$ \\
QBO & 30 \\
TNA & $100 ; 30 ; 12$ \\
TSA & $120 ; 80 ; 30 ; 17 ; 10$ \\
\hline
\end{tabular}

observou-se um maior número de eventos La Niña (Mantua et al., 1997), com possível influências entre escalas interdecadal - interanual, dado que a PDO pode influenciar a frequência dos eventos ENOS dependendo da fase (Kayano e Andreoli, 2009a). Assim, a as correlações positivas do primeiro CP com a PDO e ENOS sugerem a influência destes fenômenos na vazão na região central da Bacia do Paraná, favorecendo a ocorrência de vazões maiores (menores) durante a ocorrência de eventos El Niño/PDO positiva (La Niña/PDO negativa).

O segundo CP explica $23,4 \%$ da variância original dos dados e evidencia variabilidades opostas entre o Sul Brasil (incluindo as Bacias do Uruguai, Paraná, exceto a parte alta, e Atlântico Sudeste) e as Regiões Central-norte e Nordeste, principalmente sobre as Bacias do São Francisco 
e Tocantins, incluindo também a parte alta da Bacia do Paraná (Fig. 3). A série temporal apresenta picos significativos nas escalas interanual (43,6 meses) e semianual (4, 5 e 6 meses), a série temporal do CP possui correlações significativas com os índices N3.4 e IOS, que aumentam com a defasagem. Em adição, esse CP apresenta correlações significativas com índices associados a variabilidades no Oceano Atlântico, destacando-se o TSA em todas as defasagens, o AMM para as defasagens mais altas e o NAO para até 1 mês de defasagem. Verificou-se também associação com o Índice do Oceano Índico (IOD) com 1 e 2 meses de defasagem.

Os resultados indicam que o segundo CP pode estar relacionado aos padrões climáticos representados pelos índices anteriores, com o ENOS modulando a escala interanual, e o TSA e a NAO influenciando a escala semianual. A inter-relação do ENOS com as anomalias no Atlântico tropical afeta a precipitação no Nordeste do Brasil, com sinal de influência dependente das fases associadas (Andreoli e Kayano, 2007), podendo também afetar a vazão de rios nessa região, conforme indicado por este segundo $\mathrm{CP}$. Na mesma frequência de 43 meses também podemos destacar os índices IOS e IOD.

Tanto o padrão espacial quanto o temporal deste CP é semelhante ao padrão clássico de impacto do ENOS sobre a precipitação no Brasil (Ropelewski e Halpert, 1987), dado que a variabilidade interanual é a que mais se destaca, sem indicar a modulação pela PDO (capturada no primeiro $\mathrm{CP}$ ) indica vazões mais altas (baixas) em anos de El Niño (La Niña) nas regiões onde os pesos do CP são positivos (negativos). De acordo com Weare e Nasstrom (1982), os episódios ENOS podem apresentar diferenças no padrão

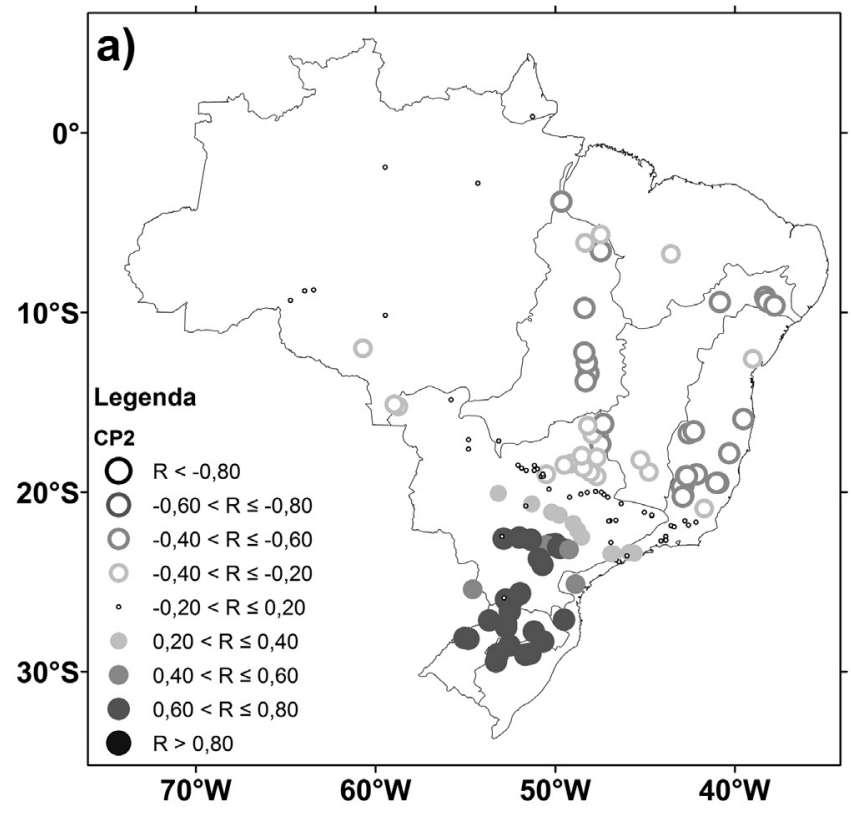

espacial ao longo de suas fases. Assim, sugere-se que estes dois primeiros CPs indicam que as diferentes fases do ENOS podem afetar vazões em regiões distintas. Dettinger et al. (2000) e Ward et al. (2014) mostraram um padrão oposto nas correlações entre a vazão de rios sobre as Regiões Nordeste e Sul do Brasil e o ENOS.

Explicando cerca de $9 \%$ da variância dos dados, o terceiro $\mathrm{CP}$ possui padrão espacial com coeficientes negativos no Brasil central-norte (Bacias do Tocantins, São Francisco e alto Paraná) e no Sul do Brasil (Bacias do Uruguai, Atlântico Sudeste e baixo Paraná) e de sinal oposto na porção central e leste da Bacia do Paraná, conforme apresentado na Fig. 4, sendo que sua série temporal apresenta picos significativos nas escalas interanual (30 meses), interdecadal (137 meses) e intrasazonal (3 meses).

Os padrões climáticos de baixa frequência associados com o primeiro CP (PDO, Niño 3.4, IOS, AMO) são também significativamente correlacionados com esse $\mathrm{CP}$, mas neste caso invertem os sinais das correlações com os índices de PDO e ENOS, sendo negativas.

Este CP apresenta correlações defasadas positivas significativas com a AAO (lags 1 a 3), que se associa a atividade de transientes (como ciclones) e com as variabilidades interanual e intrasazonal (Carvalho et al., 2005), podendo influenciar anomalias de precipitação e de vazão na região destacada. É conhecido que há uma tendência a ocorrer vazões mais altas (baixas) na Bacia do Uruguai na fase negativa (positiva) da AAO (Oliva e Silva, 2011).

Apesar da presença dos picos de baixa frequência, o padrão deste $\mathrm{CP}$ também pode estar associado ao posicionamento da Zona de Convergência do Attântico Sul (ZCAS), que atua na escala intrasazonal, variando sua posi-

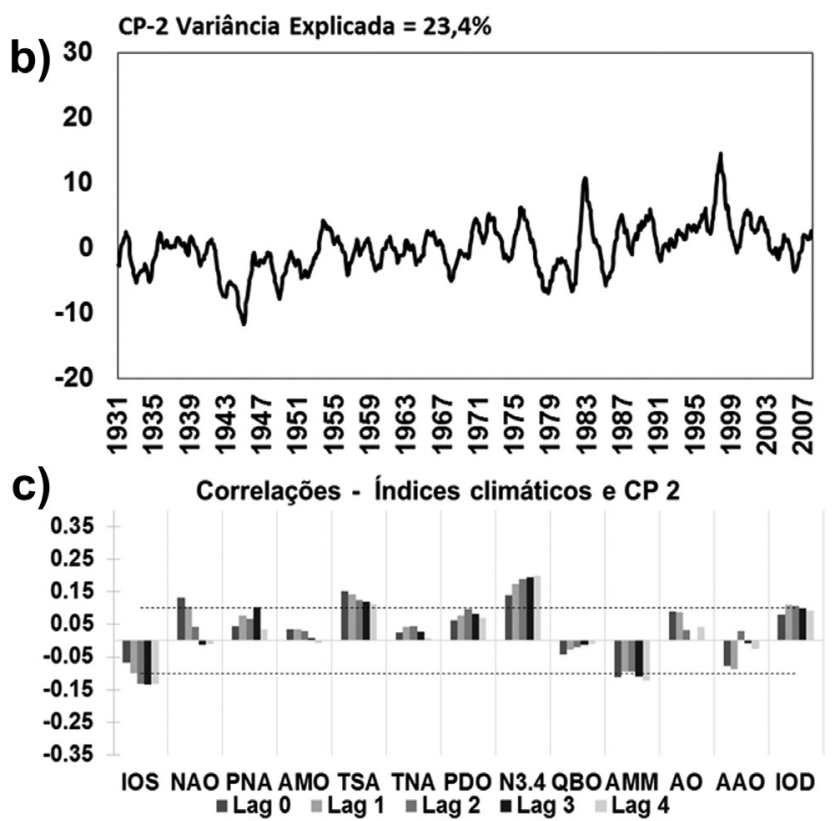

Figura 3 - Padrão espacial do segundo componente principal de vazão (CP2) (a); Série temporal suavizada pela média móvel de 13 meses do CP2 (b) e Correlações do CP2 com os índices climáticos indicados (c) (correlações são significativas a partir da linha tracejada). 

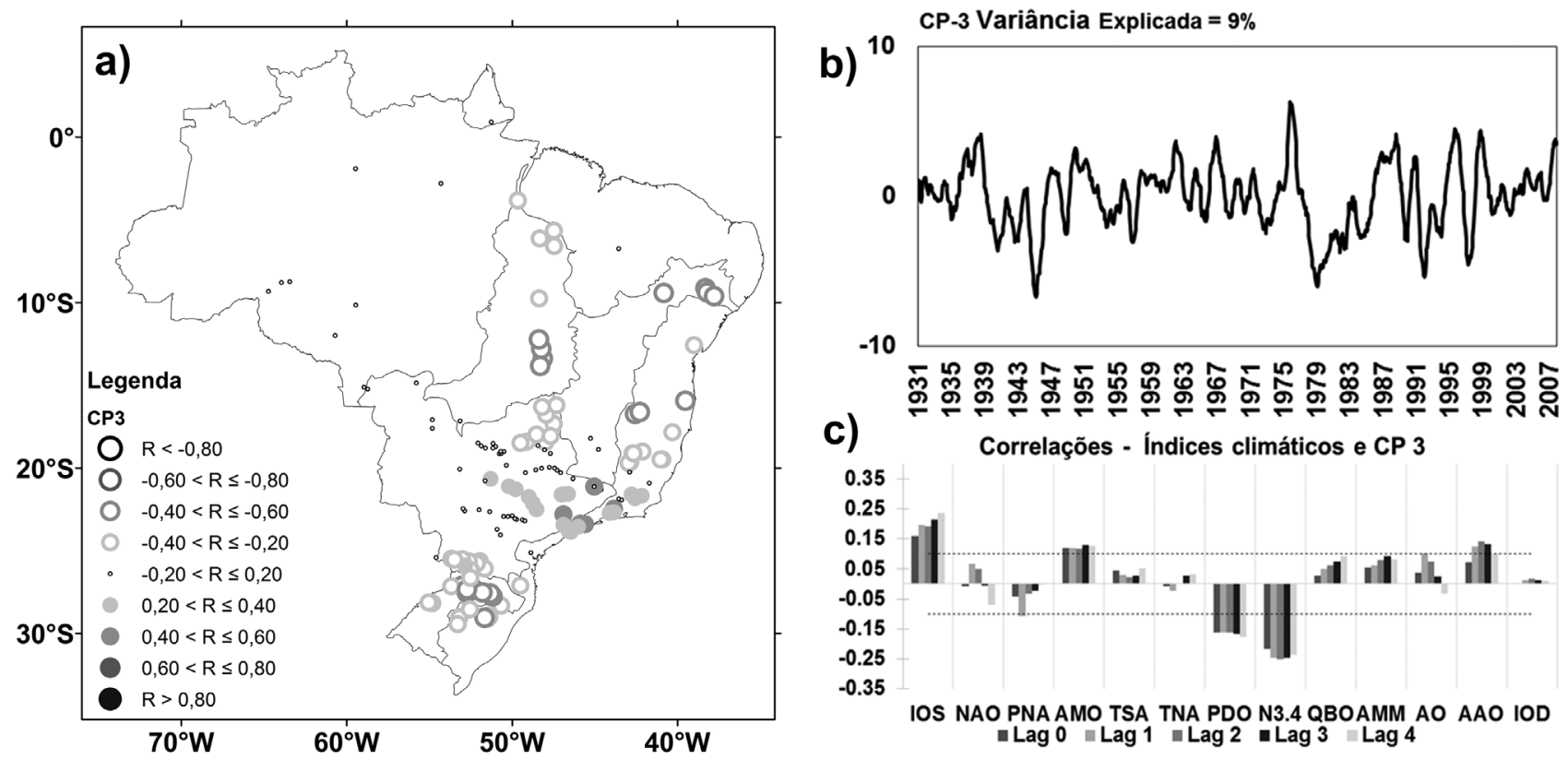

Figura 4 - Padrão espacial do terceiro componente principal de vazão (CP3) (a); Série temporal suavizada pela média móvel de 13 meses do CP3 (b) e Correlações do CP3 com os índices climáticos indicados (c) (correlações são significativas a partir da linha tracejada).

ção no Sudeste do Brasil. Ferraz (2004) identificou um modo intrasazonal de precipitação com forte componente na ZCAS e sinal oposto no norte do Nordeste brasileiro e sul da América do Sul. A ZCAS ocorre principalmente no verão, quando o Sistema de Monções da América do Sul (SMAS) é atuante, transportando umidade da região Amazônica para o Brasil central-leste. Há indícios da conexão entre variabilidades interanual e intrasazonal, dada a relação dos eventos ENOS e o SMAS. É possível que efeitos locais, combinados com efeitos de grande escala, sejam responsáveis por mudanças bruscas nas anomalias precipitação relacionadas ao SMAS em parte do verão, de anos de eventos El Niño e La Niña (Grimm, 2003; Grimm, 2004), sendo que esses impactos variam com as fases do ENOS.

$\mathrm{O}$ quarto $\mathrm{CP}$ explica $6,2 \%$ da variância da vazão (Fig. 5) e destaca um dipolo leste-oeste entre o Sudeste e o Centro-Oeste do país, com coeficientes mais altos e positivos sobre a faixa norte da Bacia do Paraná (Rio Para-
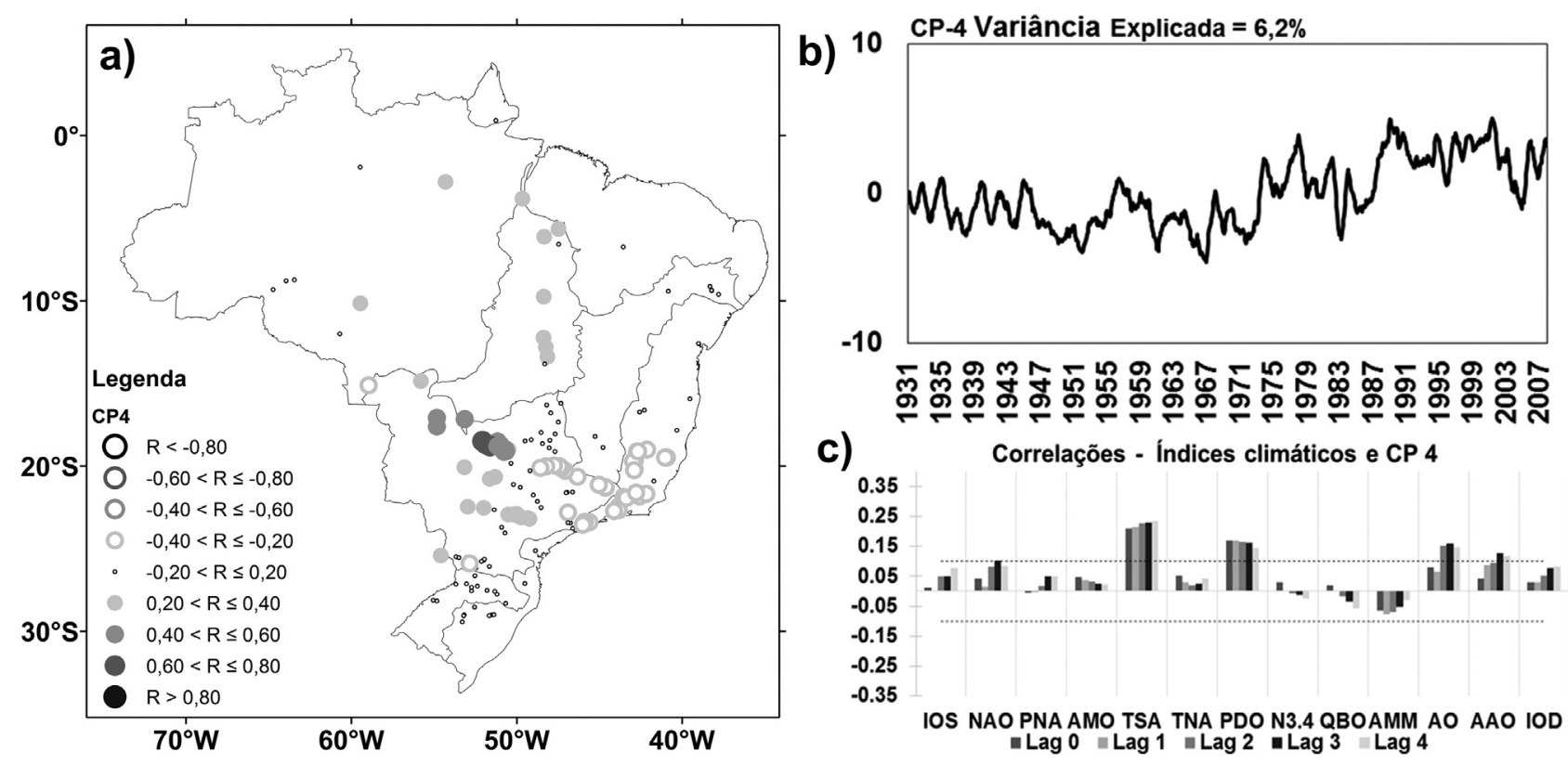

Figura 5 - Padrão espacial do quarto componente principal de vazão (CP4) (a); Série temporal suavizada pela média móvel de 13 meses do CP4 (b) e Correlações do CP4 com os índices climáticos indicados (c) (correlações são significativas a partir da linha tracejada). 
naíba), e coeficientes negativos sobre o leste dessa bacia (Rio Grande) e na Bacia do Atlântico Leste. A série temporal do CP apresenta flutuações com picos significativos nas escalas intrasazonal e semianual (4 e 5 meses, respectivamente), destaca-se uma mudança no padrão da série durante a década de 70, passando a ter o predomínio de ciclos interdecadais e scores positivos. A série temporal possui correlações significativas positivas com os índices PDO e TSA em todas as defasagens, sendo também verificadas correlações positivas menores com os índices de variabilidades polares (AO e AAO). Na análise dos picos espectrais dos índices (Tabela 2), o índice PDO além das frequências mais lentas, apresenta também frequências mais altas significativas. O pico interdecadal de mais baixa frequência, na série do CP não foi detectado, mas o de mais alta sim, o que pode explicar a correlação encontrada entre o CP e o PDO.

Molion (2008) relata a influência da PDO sobre a precipitação no Brasil central, sudeste da Amazônia e sul do Brasil, destacando um período de baixas precipitações de 1947 a 1976, durante a fase fria da PDO e maiores precipitações de 1977 a 1998, durante a fase quente. Os picos representativos nas escalas intrasazonal e semianual podem estar associados às correlações com os transientes (influenciada pelo AAO) e o pelo TSA, que juntos podem impactar a atuação do SMAS no Sudeste brasileiro. A aparente mudança no sinal dos scores após meados de 1970 pode estar associada às variabilidades decadal e multidecadal.

Com variância explicada de 4,5\%, o quinto CP apresenta um padrão espacial semelhante ao de um trem de onda número 2 , entre o sul e o norte do país. Coeficientes distintos vão se alternando entre as bacias Uruguai, faixa sul das Bacias do Paraná e do Atlântico Sudeste, faixa norte da Bacia do Paraná e Bacias do Tocantins e São Francisco, sendo destacados os coeficientes positivos mais altos sobre o extremo sul do país (Fig. 6). A série temporal deste CP apresenta picos significativos nas escalas semianual e intrasazonal (6 a 4 meses), decadal (137 meses) e multidecadal (240 meses). A partir da década de 70 a série temporal do CP passa a ter uma pequena tendência de aumento associada com variações temporais em escala interanual e de mais alta frequência. Esta tendência de aumento pode estar relacionada com a possível conexão entre escalas, isto é, modulação da oscilação interdecadal sobre a interanual, ou a fatores locais, pelo uso inadequado da terra e alteração dos sistemas hídricos na região destacada no CP (Tucci, 2004).

Os índices climáticos correlacionados significativamente com o quinto CP são de processos provenientes de regiões dos Oceanos Atlântico, Pacífico e Índico (Fig. 7), correspondentes ao TSA com flutuações de mais alta frequência, ao AMM, PDO, N3.4 e IOS com variabilidade nas escalas decadal e interanual e ao IOD, com variações tanto interanual e semianual (Tabela 2) Estes resultados concordam com o observado na análise espectral, que indica a relação do CP com o TSA, IOD, PDO e o AMM.

$\mathrm{O}$ sexto $\mathrm{CP}$ (Fig. 7) explica apenas uma pequena variância dos dados originais $(3,3 \%)$, destacando coeficientes positivos sobre a parte alta da Bacia do Paraná e negativos nas demais bacias, com destaque para as Bacias do Tocantins e faixa sul da Bacia do Atlântico Leste. Sua série temporal apresenta principalmente picos significativos na escala semianual a intrasazonal (6 a 3 meses) e na escala interdecadal (120 meses). Correlações significativas
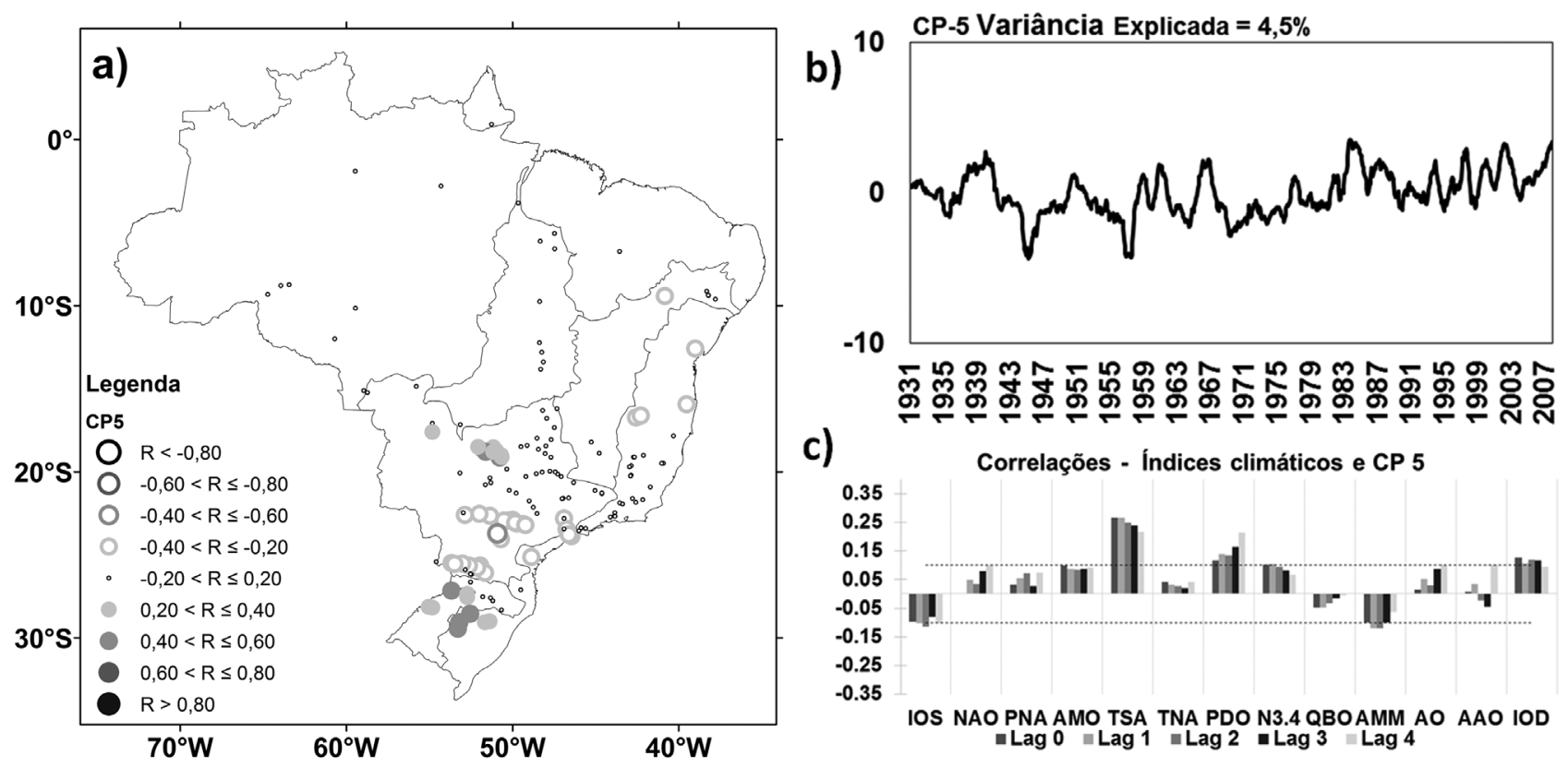

Figura 6 - Padrão espacial do quinto componente principal de vazão (CP5) (a); Série temporal suavizada pela média móvel de 13 meses do CP5 (b) e Correlações do CP5 com os índices climáticos indicados (c) (correlações são significativas a partir da linha tracejada). 

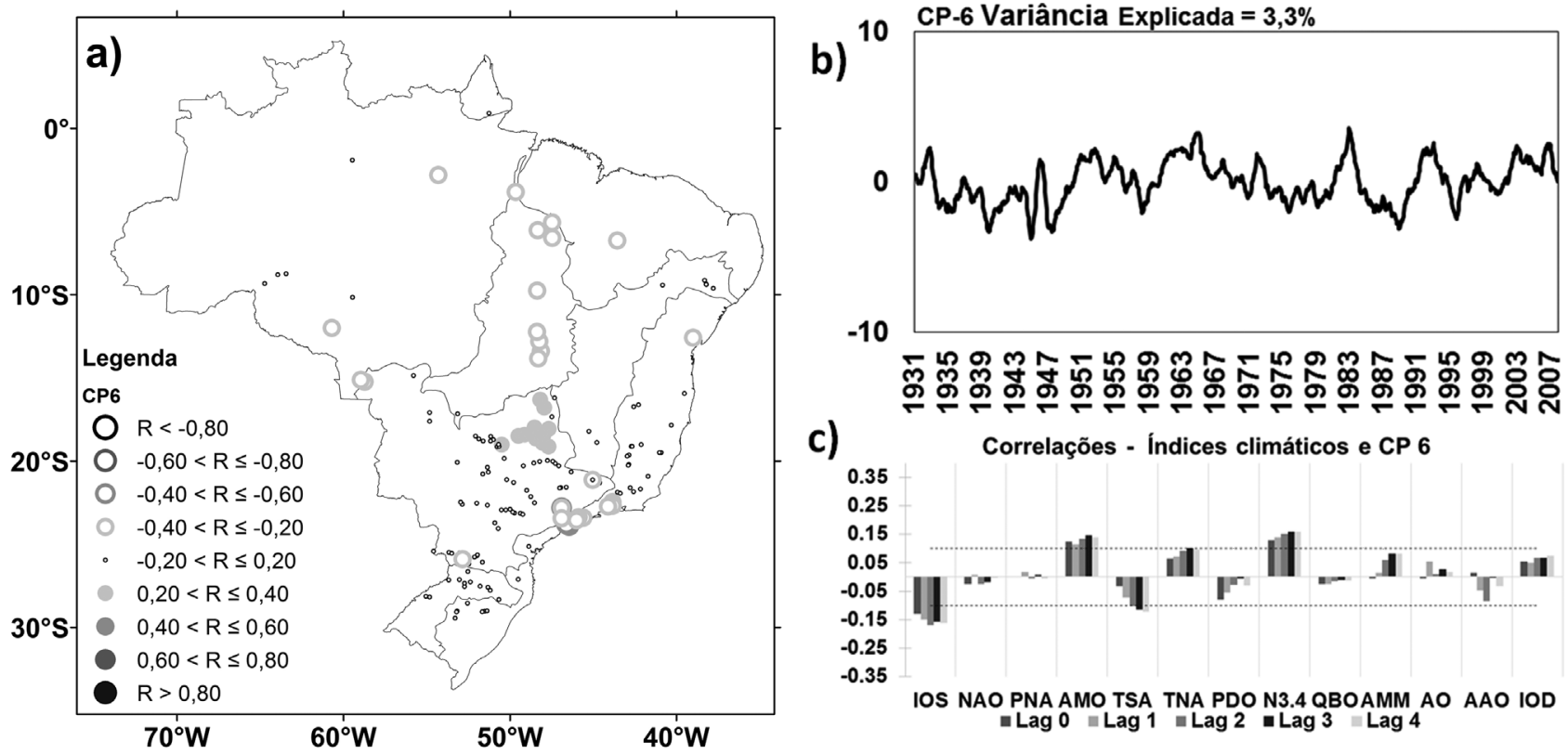

Figura 7 - Padrão espacial do sexto componente principal de vazão (CP6) (a); Série temporal suavizada pela média móvel de 13 meses do CP5 (b) e Correlações do CP6 com os índices climáticos indicados (c) (correlações são significativas a partir da linha tracejada).

são verificadas com índices que representam padrões de variabilidades nas escalas anteriores e que provavelmente modulem essas variações presentes na vazão de rios (Fig. 7), tais como: IOS e Niño 3.4; AMO; TSA ( $\operatorname{lag} 2$ a 4). Resultados da análise espectral destacam picos significativos na escala semianual a intrasazonal ( 6 a 3 meses), que podem estar associado à influência das anomalias de TSM no Atlântico tropical (TSA), e decadal (120 meses), via AMO. Estes períodos concordam com os observados na Tabela 2 para os mesmos índices.
A Tabela 3 apresenta uma síntese dos principais resultados obtidos neste trabalho. Os principais CPs de variabilidade de vazão de rios apresentam flutuações interanuais associadas ao ENOS e correlações significativas com a TSM no Atlântico tropical (principalmente, via TSA), o que evidencia a importância das variabilidades climáticas tropicais para as variações nas vazões de rios no Brasil. Padrões climáticos associados com variabilidades decadal e multidecadal, tanto do Atlântico como do Pacífico, também apresentam relações persistentes com os principais

Tabela 3 - Principais resultados obtidos: bacias destacadas em cada um dos Componentes Principais (CPs) sinal (+) indicam correlações positivas e (-) negativas, escala temporal dos picos espectrais das séries temporais dos CPs e índices de teleconexão que apresentam correlação significativa com as series temporais dos CPs onde sinal (+) indicam correlações positivas e (-) negativas.

\begin{tabular}{|c|c|c|c|}
\hline \multirow[t]{2}{*}{$\mathrm{CP}$} & \multirow[t]{2}{*}{ Bacias destacadas } & \multicolumn{2}{|c|}{ Série Temporal do CP } \\
\hline & & Picos espectrais significativos & Correlação significativa com índices de teleconexão \\
\hline 1 & $\begin{array}{l}\text { Paraná (Oriental) }(+) \text {, Tocantins }(+), \\
\text { Atlântico Leste }(+) \text { e São Francisco }(+)\end{array}$ & Semianual, interanual e decadal & Niño 3.4(+), PDO (+), IOS (-), AMO (-), TSA (-) \\
\hline 2 & $\begin{array}{l}\text { Uruguai (+), Atlântico Sudeste (+), Paraná } \\
\text { (centro-sul) (+), Atlântico Leste (-), alto } \\
\text { Paraná (-)Tocantins (-) e São Francisco (-) }\end{array}$ & Interanual e semianual & $\begin{array}{l}\text { Niño } 3.4(+) \text {, TSA }(+), \operatorname{IOD}(+), \text { NAO }(+), \\
\text { IOS (-), AMM (-) }\end{array}$ \\
\hline 3 & $\begin{array}{l}\text { Paraná (central e leste) (+), baixo Paraná } \\
(-) \text {, Uruguai (-) e Atlântico Sudeste (-) }\end{array}$ & Interanual, interdecadal e intrasazonal & $\operatorname{IOS}(+), \operatorname{AMO}(+)$, AAO (+), PDO (-), Niño 3.4(-) \\
\hline 4 & $\begin{array}{l}\text { Paraná (norte) (+), Amazônica (sul) } \\
(+), \text { Tocantins (norte) }(+) \text {, Atlântico } \\
\text { Leste (sul) }(-)\end{array}$ & Intrasazonal e interanual & $\mathrm{TSA}(+), \operatorname{PDO}(+), \mathrm{AO}(+), \mathrm{AAO}(+)$ \\
\hline 5 & $\begin{array}{l}\text { Uruguai (+), Atlântico Sudeste (leste) } \\
(+) \text {, Paraná (central-sul) (-), Paraná (norte) } \\
(+) \text {, São Francisco (-), Atlântico Leste (-) }\end{array}$ & Semianual e intrasazonal & $\begin{array}{l}\text { Niño } 3.4(+), \text { TSA }(+), \text { PDO }(+), \text { AO }(+), \\
\text { IOD }(+), \operatorname{AMM}(-), \operatorname{IOS}(-)\end{array}$ \\
\hline 6 & $\begin{array}{l}\text { Alto Paraná (+), Tocantins (-) e Atlântico } \\
\text { Leste (sul) (-) e Amazônica (-) }\end{array}$ & Semianual a intrasazonal & AMO (+), Niño $3.4(+)$, IOS (-), TSA (-) \\
\hline
\end{tabular}


CPs de vazão, exceto para o caso do segundo componente principal.

\section{Conclusões}

A variabilidade climática é um fator condicionante para as variações dos recursos hídricos do Brasil, que apresenta grande variabilidade espacial e temporal devido às características climáticas ao longo do território e a fisiologia das bacias. No presente estudo foram investigadas os principais modos de variabilidade de vazão nas principais bacias hidrográficas brasileiras cujos padrões temporais e espaciais podem estar relacionados com padrões de variabilidade climática, sendo identificadas claras relações entre as variações nas vazões e conhecidos padrões de variabilidade climática.

$\mathrm{O}$ primeiro $\mathrm{CP}$ de vazão destaca a importância das variabilidades na TSM do Pacífico e Atlântico, tropical e norte. As análises evidenciam a modulação da PDO sobre o ENSO e o impacto de mesmo sinal que a fase dessa oscilação, sobre a maior parte do país, principalmente na Bacia do Paraná. O Atlântico influencia tanto em escala multidecadal (AMO) como em mais alta frequência, através das variações nas anomalias de TSM sobre a faixa tropical sul (TSA).

Os dois primeiros componentes principais de vazão de rios possuem variabilidades interanuais, completadas por flutuações de mais alta frequência. No entanto, no caso do segundo $\mathrm{CP}$, tanto as variações temporais quanto o padrão espacial são semelhantes ao padrão clássico do ENOS e, diferente do primeiro $\mathrm{CP}$, não caracteriza a modulação pela PDO, destacando coeficientes positivos sobre as Bacias do Uruguai e Atlântico Sudeste e negativos principalmente sobre as Bacias do São Francisco e Tocantins,. Este CP também indica a importância da inter-relação do ENOS com as anomalias de TSM no Atlântico tropical e norte (via, TSA e NAO), que podem afetar a vazão de rios.

$\mathrm{O}$ terceiro $\mathrm{CP}$ destaca um tripolo com coeficientes negativos sobre o Sul do Brasil, positivos sobre leste do Sudeste e negativos sobre parte do Brasil central-norte. Tal padrão pode estar relacionado ao posicionamento da ZCAS, em escala intrasazonal, e com o transporte de transientes, cuja variação pode ser influenciada pela Oscilação Antártica (AAO), que apresenta flutuações na escala intrasazonal e de mais baixa frequência (interanual).

Os componentes principais de mais alta ordem $(\mathrm{CP} 4$, CP 5 e CP 6) e de menor explicação da variância apresentam uma clara modulação de flutuações de mais baixa frequência. Nos casos dos CPs 4 e 5 , verificam-se mudanças em meados dos anos de 1970, sendo verificadas mais flutuações de baixa frequência posteriores a esse período (associadas com PDO) e anteriores ao mesmo (relacionadas à $\mathrm{PDO}$ e $\mathrm{AMM}$ ), no $\mathrm{CP} 4 \mathrm{e} \mathrm{CP} 5$, respectivamente. Para o sexto CP são verificadas correlações significativas com AMO e com o ENOS. Para tais CPs também se destacam relações com padrões climáticos de mais alta frequência, como: TSA, AO e AAO, no caso do CP 4; TSA e IOD, com CP 5; e somente TSA com CP 6.

Os resultados desse estudo indicam a importância de serem levadas em conta as influências de variabilidades climáticas para o entendimento de variações nas vazões de rios. Deste modo, sugere-se que a consideração de índices dos padrões climático destacados para estimativas de vazão poderá contribuir para o aprimoramento de modelos preditivos, dado que há correlações significativas defasadas entre tais variáveis e flutuações semelhantes.

\section{Agradecimentos}

Ao CNPq (Projeto Universal: $\mathrm{n}^{\circ} 480683 / 2010-7, \mathrm{n}^{\circ}$ 304688/2012-6, $\mathrm{n}^{\mathrm{o}}$ 471700/2013-4, Bolsa Pq 304688/2012-6) e FAPERGS (Projeto PRONEM).

\section{Referências}

AMARASEKERA， K.N.; LEE， R.F.; WILLIAMS， E.R.; ELTAHIR, E.A. ENSO and the natural variability in the flow of tropical rivers. Journal of Hydrology, v. 200, n. 1, p. 24-39, 1997.

ANDREOLI, R.V.; KAYANO, M.T. A importância relativa do Atlântico Tropical Sul e Pacífico leste na variabilidade de precipitação do Nordeste do Brasil. Revista Brasileira de Meteorologia, v. 22, n. 1, p. 63-74. 2007.

BERRI, G.J.; GHIETTO, M.A.; GARCIA, N.O. The influence of ENSO in the flows of the Upper Paraná River of South America over the past 100 years. Journal of Hydrometeorology, v. 3, n. 1, p. 57-65, 2002.

CARDOSO, A.O.; CATALDI, M. Relações de índices climáticos e vazão de rios no Brasil. In: Anais: XVII Congresso Brasileiro de Meteorologia, Gramado-RS, 2012. Anais do XVII CBMET, SBMET, Rio de Janeiro. Acesso em: 1 dez. 2012.

CARDOSO, A.O.; HAMBURGER, D.S.; FERRAZ, S.T.E. Critérios para regionalização de vazão de rios ao longo do Brasil. Ciência e Natura, Ed. Suplementar, p. 343-346, 2011.

CARDOSO, A.O.; SILVA DIAS, P.L. The relationship between ENSO and Paraná River flow. Advances in Geosciences, v. 6, p. 189-193, 2006.

CARVALHO, L.M.V.; CHARLES, J., AMBRIZZI, T. Opposite Phases of the Antarctic Oscillation and Relationships with Intraseasonal to Interannual Activity in the Tropics during the Austral Summer Journal of Climate, v. 18, p. 702-718, 2005.

CHAHINE, M.T. The hydrological cycle and its influence on climate. Nature, v. 359, n. 6394, p. 373-380, 1992.

CHATFIELD, C. The analysis of time series, an introduction, sixth edition: New York, Chapman \& Hall/CRC. 2004.

CHIANG, J.; KUSHNIR, Y.; GIANNINI, A. Reconstructing Atlantic Intertropical Convergence Zone variability: Influence of the local cross-equatorial sea surface temperature gradient and remote forcing from the eastern equatorial Pacific. Journal of Geophysical. Research., v. 107, n. D1, ACL3, 2002.

Chow, V.T.; Maidment, D.R.M.; Saldarriaga, L.W.; Juan, G. Hidrologia aplicada. McGraw-Hill, Santafé de Bogotá, Colombia, 1994. 
COELHO, C.A.S.; MARENGO J.A. ; CAVALCANTI, I.A.F. ; COSTA, S.M.S. ; FREITAS, S.R. ; ITO, E. et al. Climate diagnostics of three major drought events in the Amazon and illustrations of their seasonal precipitation predictions. Meteorological Applications, v. 19, p. 237-255, 2012.

COELHO, C.A.S.; UVO, C.B.; AMBRIZZI, T. Exploring the impacts of the tropical Pacific SST on the precipitation patterns over South America during ENSO periods. Theoretical and Applied. Climatology, v. 71, p. 185-197, 2002.

D'ALMEIDA, C. Oscilações Intrasazonais de Precipitação na Estação Chuvosa em São Paulo e Condições Atmosféricas Associadas. Dissertação de Mestrado. Departamento de Ciências Atmosféricas, IAG/USP, 113 p, 1997.

Dettinger, M.D.; Cayan, D.R.; McCabe, G.M.; Marengo, J. A. Multiscale streamflow variability associated with El Nino/Southern Oscillation. In: Diaz, H. F.; Markgraf, V. El Nino and the Southern Oscillation. New York: Cambridge University Press, 2000. p. 114-147.

DETTINGER, Michael D.; DIAZ, Henry F. Global characteristics of stream flow seasonality and variability. Journal of Hydrometeorology, v. 1, n. 4, p. 289-310, 2000.

FERRAZ, S. E. T. Variabilidade Intrasazonal no Brasil e Sul da América do Sul. 2004. 124 f. Tese (Doutorado em Meteorologia). Departamento de Ciências Atmosféricas, IAG-USP, São Paulo, 2004.

GUETTER, ALEXANDRE K.; PRATES, JOSÉ E. Degrau climático nas séries de vazões das bacias brasileiras. Anais: XII Congresso Brasileiro de Meteorologia, Foz do Iguaçu. 2002. p. 2099-2110.

GRIMM, A.M. The El Nino impact on the summer monsoon in Brazil: Regional processes $v$ s. remote influences. Journal of Climate, v. 16, n. 2, p. 263-280, 2003.

GRIMM, A.M. How do La Niña events disturb the summer monsoon system in Brazil? Climate Dynamics, v. 22, p. 123138, 2004.

GRIMM, A.M. Variabilidade Interanual do Clima no Brasil. In: I. F. A. Cavalcanti, N. J. Ferreira, M. G. A. J. Silva, A. F. da Silva Dias. Tempo e Clima no Brasil. 1 ed. São Paulo: Oficina de Textos, v. 1, p. 213-233, 2009.

GRIMM, A.M.; FERRAZ, S.E.T.; BARROS, V.R.; DORELO, M.B. Intraseasonal variations of the South American Summer Rainfall. CLIVAR Exchanges, v. 5, p. 13-14, 2000.

Grimm, A.M.; Ferraz, S.T.; Gomes, J. Precipitation Anomalies in Southern Brazil Associated with El Niño and La Niña Events. Journal of Climate, v. 11, p. 2863-2880, 1998.

Grimm, A.M.; TEDESCHI, R.G. ENSO and extreme rainfall events in South America. Journal of Climate, v. 22, p. 1589-1609, 2009.

JENKINS, G.M.; WATTS, D.G. Spectral Analysis and its applications. Oakland: Holden-Day, 1968.

KAYANO, M.T.; ANDREOLI, R.V. Clima da Região Nordeste do Brasil. In: I. F. A. Cavalcanti, N. J. Ferreira, M. G. A. J. Silva, A. F. da Silva Dias. Tempo e Clima no Brasil. 1 ed. São Paulo: Oficina de Textos, v. 1, p. 213-233, 2009a.

KAYANO, M.T.; ANDREOLI, R.V. Variabilidade Decenal a Multidecenal. In: I. F. A. Cavalcanti, N. J. Ferreira, M. G. A. J. Silva, A. F. da Silva Dias. Tempo e Clima no Brasil. 1 ed. São Paulo: Oficina de Textos, v. 1, p. 375-383, 2009 b.

KODAMA, Y.M. Large-scale common features of sub-tropical precipitation zones (the Baiu Frontal Zone, the SPCZ, and the SACZ). Part I: characteristics of subtropical frontal zones. Journal of the Meteorological Society of Japan, v. 70, p. 813-835, 1992.

KOUADIO, Y.K.; SERVAIN, J.; MACHADO, L.A.T.; LENTINI, C.A.D. Heavy Rainfall Episodes in the Eastern Northeast Brazil Linked to Large-Scale Ocean-Atmosphere Conditions in the Tropical Atlantic. Advances in Meteorology, v. 2012, p. 1-16, 2012.

Kousky, V.E. Pentad outgoing longwave radiation climatology for the South American sector. Revista Brasileira de Meteorologia, v. 3, n. 1, p. 217-231, 1988.

KOUSKY, V.E.; CAVALCANTI, I.F.A. Eventos Oscilação Sul El Niño: características, evolução e anomalias de precipitação. Ciência e Cultura, v. 36, n. 11, p. 1888-1889, 1984.

LIEBMANN, B.; KILADIS, G.N.; MARENGO J. A.; AMBRIZZI, T. Submonthly Convective Variability over South America and the South Atlantic Convergence Zone. Journal of Climate, v. 12, p. 1877-1891, 1999.

LIEBMANN, B.; VERA, C.S.; CARVALHO, L.M.V.; CAMILLONI, I.A.; HOERLING, M.P.; ALLURED, D.; BARROS, V.R.; BÁEZ, J.; BIDEGAIN, M. An Observed Trend in Central South American Precipitation. Journal of Climate, v. 17, p. 4357-4367, 2004.

LIMA, J. E. F. W.; MONTENEGRO, S.; DE ASSUNÇÃO MONTENEGRO, A. A.; KOIDE, S. Comparative hydrology: relationships among physical characteristics, hydrological behavior, and results of the SWAT model in different regions of Brazil. Revista Brasileira de Geografia Física, v. 7, n. 6, p. 1187-1195, 2015.

MANTUA, N.J.; HARE, S.R.; ZHANG, Y.; WALLACE, J.M.; FRANCIS, R.C.A. Pacific interdecadal climate oscillation with impacts on salmon production. Bulletin of the American Meteorological Society, v. 78, p. 1069-1079, 1997.

MARENGO, J.A.; NOBRE, C.A. Clima da Região Amazônica. In: I.F.A. Cavalcanti, N.J. Ferreira, M.G.A.J. Silva, A.F. da Silva Dias. Tempo e Clima no Brasil. 1 ed. São Paulo: Oficina de Textos, v. 1, p. 197-212, 2009.

MARENGO J.A.; TOMSASELLA, J.; SOARES, W.; ALVES, L.M.; NOBRE, C. Extreme climatic events in the Amazon basin: climatological and hydrological context of previous floods. Theoretical and Applied Climatology, v. 85, p. 1-13, 2011.

MIAO, C.; NI, J. Variation of natural streamflow since 1470 in the Middle Yellow River, China. International Jurnal of Environmental Research and Public Health, v. 6, n. 11, p. 2849-2864, 2009.

MOLION, L.C.B. Perspectivas climáticas para os próximos 20 anos. Revista Brasileira de Climatologia, v. 3, p. 117-128, 2008.

MOURA, A.D.; SHUKLA, J. On the dynamics of droughts in northeast Brazil: observations, theory and numerical experiments with a general circulation model. Journal of the Atmospheric Sciences, v. 38, p. 2653-2675, 1981.

MILLY, P.C.D; DUNNE, K.A.; VECCHIA, A.V. Global pattern of trends in streamflow and water availability in a changing climate. Nature, v. 438, p. 347-50, 2005.

OLIVA, F.G.; SILVA, M.G.A.J. Opposite Phases of the Antarctic Oscillation and Relationships with Precipitation and Discharges in the Uruguai River Hydrographic Region, South Region of Brazil. In: IV Simpósio Internacional de Climatologia, 2011, João Pessoa/PB. Mudanças Climáticas e 
seus Impactos em Áreas Urbanas, 2011. Anais: IV SIC, SBMET, Rio de Janeiro. Acesso em: 1 fev. 2014.

PAEGLE, J. N.; BYERLE L. A.; MO E K. C. Intraseasonal Modulation of South American Summer Precipitation, Monthly Weather Review, v. 128, 837-850, 2000.

Pruski, F.F.; Brandão, V.S.; Silva, D.D. Escoamento superficial. Editora UFV, Universidade Federal de Viçosa, 2004. 87 p

Quadro, M.F.L; Machado, L.H.L.; Calbete, S.; Batista, N.N.M., Oliveira, G. S. Climatologia de Precipitação e Temperatura no período de 1986 a 1996. Climanálise Especial, Edição Comemorativa de 10 anos, 1996.

REBOITA, M.S.; M.S., Gan, M.A.; da Rocha, R.P.; Ambrizzi, T. Regimes de precipitação na América do Sul: uma revisão bibliográfica. Revista Brasileira de Meteorologia, v. 25, n. 2, p. 185-204, 2010.

Robertson, A.W.; Mechoso, C.R. Interannual and decadal cycles in river flows of southeastern South America. Journal of Climate, v. 11, n. 10, p. 2570-2581, 1998.

ROPELEWSKI, C.F.; HALPERT, M.S. Global and regional scale precipitation patterns associated with the El Niño / Southern Oscillation, Monthly Weather Review., v. 115, n. 11, p. 1606-1626, 1987.

SAHU, N.; BEHERA, S.K.; RATNAM, J.V.; DA SILVA, R.V.; PARHI, P.; DUAN, W.; TAKARA, K.; SING, R.; YAMAGATA, T. El Niño Modoki connection to extremely-low streamflow of the Paranaíba River in Brazil. Climate dynamics, v. 42, n. 5-6, p. 1509-1516, 2014.

SAJI N.H.; GOSWAMI B.N.; VINAYACHANDRAN P.N.; YAMAGATA, T. A dipole mode in the tropical Indian Ocean, Nature, 401, n. 6751, p. 360-363, 1999.
TEDESCHI, R.G.; GRIMM, A.M. Variações significativas de eventos extremos de precipitação e de vazão durante episódios de El Niño e La Niña. In: XV Congresso Brasileiro de Meteorologia, São Paulo - SP, 2008. Anais: XV CBMET, SBMET, Rio de Janeiro. Acesso em: 11 set. 2010.

TEDESCHI, R.G.; CAVALCANTI, I.F.A.; GRIMM, A.M. Influences of two types of ENSO on South American. International Journal of Climatology, v. 33, n. 6, p. 1382-1400, 2012.

TRENBERTH, K.E.; STEPANIAK, D.P. Indices of El Niño evolution. Journal of Climate, v. 14, n. 8, p. 1697-1701, 2001.

TUCCI, C.E.; CLARKE, R.T. Impacto das mudanças da cobertura vegetal no escoamento: revisão. Revista Brasileira de Recursos Hídricos, v. 2, n. 1, p. 135-152, 1997.

TUCCI, C.E.M. Visão de Recursos Hídricos da bacia do rio da Prata. GEF/CIC/OEA, 2004, 220 p.

TUCCI, C.E.M. Hidrologia: ciência e aplicação. 4 ed. Porto Alegre: Editora da UFRGS/ABRH, 2009.

VERA, C.; HIGGINS, W.; AMADOR, J.; AMBRIZZI, T.; GARREAUD, R. et al. Toward a Unified View of the American Monsoon Systems. Journal of Climate, v. 19, n. 20, p. 4977-5000, 2006.

WEARE, B.C.; NASSTROM, J.S. Examples of Extended Empirical Orthogonal Function Analyses. Monthly Weather Review, v. 110, n. 6, p. 481-485, 1982.

Wilks, D.S. Statistical methods in the atmospheric sciences Academic Press, 1995.

This is an Open Access article distributed under the terms of the Creative Commons Attribution Non-Commercial License which permits unrestricted non-commercial use, distribution, and reproduction in any medium provided the original work is properly cited. 